\title{
Knockdown of TMED3 inhibits cell viability and migration and increases apoptosis in human chordoma cells
}

\author{
JINXING YANG $^{1 *}$, HANWEN HUANG $^{2 *}$, DAN XIAO $^{3 *}$, YANG DUAN $^{2}$, YANFANG ZHENG $^{4,5}$ and ZHONG CHEN $^{2}$ \\ ${ }^{1}$ Department of Orthopedic Surgery, The First Affiliated Hospital of Shenzhen University, Shenzhen, Guangdong 518035; \\ ${ }^{2}$ Department of Spinal Surgery, Zhujiang Hospital, Southern Medical University, Guangzhou, Guangdong 510282; \\ ${ }^{3}$ Department of Spine Surgery, Orthopedics Center, Guangdong Provincial People's Hospital, Guangdong Academy of \\ Medical Sciences, Guangzhou, Guangdong 510080; ${ }^{4}$ Department of Medical Oncology, Affiliated Cancer Hospital \\ and Institute of Guangzhou Medical University, Guangzhou, Guangdong 510095; ${ }^{5}$ Department of Oncology, \\ Zhujiang Hospital, Southern Medical University, Guangzhou, Guangdong 510282, P.R. China
}

Received February 28, 2020; Accepted January 28, 2021

DOI: $10.3892 /$ ijo.2021.5195

\begin{abstract}
Chordoma is a rare low-grade tumor of the axial skeleton. Over previous decades, a range of targeted drugs have been used for treating chordoma, with more specific and effective therapies under investigation. Transmembrane Emp24 protein transport domain containing 3 (TMED3) is a novel gene reported to be a regulator of oncogenesis, cancer development and metastasis; however, its role in chordoma remains unclear. In the present study, the expression of TMED3 was investigated in chordoma cells, and the effect of TMED3 knockdown on chordoma development was examined in vitro and in vivo, followed by exploration of differentially expressed proteins in TMED3-silenced chordoma cells via an apoptosis antibody array. Reverse transcription-quantitative PCR and western blot assays were performed to determine the expression levels. It was revealed that TMED3 was highly expressed in chordoma, and that knockdown of TMED3 inhibited cell viability and migration, and enhanced the apoptosis of chordoma cells. Additionally, knockdown of TMED3 inhibited the expression of $\mathrm{Bcl}-2$, heat shock protein 27, insulin-like grow th factor (IGF)-I, IGF-II, IGF binding
\end{abstract}

Correspondence to: Professor Zhong Chen, Department of Spinal Surgery, Zhujiang Hospital, Southern Medical University, 253 Gongye Middle Avenue, Haizhu, Guangzhou, Guangdong 510282, P.R. China

E-mail: chenzhong@smu.edu.cn

Professor Yanfang Zheng, Department of Medical Oncology, Affiliated Cancer Hospital and Institute of Guangzhou Medical University, 78 Heng Zhi Gang Road, Yuexiu, Guangzhou, Guangdong 510095, P.R. China

E-mail: 18665000236@163.com

${ }^{*}$ Contributed equally

Key words: chordoma, transmembrane Emp24 protein transport domain containing 3 , apoptosis, cell viability, target therapy protein-2, Livin, Akt, CDK6 and cyclin D1 proteins, whereas MAPK9 was upregulated. Furthermore, a xenograft nude mice model demonstrated that TMED3 expression promoted tumor growth. Collectively, the present findings suggested that knockdown of TMED3 inhibited cell viability and migration, and enhanced apoptosis in chordoma cells, and that TMED3 may be a novel target for chordoma therapy.

\section{Introduction}

Chordoma, characterized by having high recurrence rate after surgery and locally invasive, as well as potentially metastatic ability, is a rare, chronic, low-grade axial skeleton carcinoma derived from remnants of the notochord from embryonic development (1). The annual incidence rate of chordoma is $\sim 0.8$ per million people, accounting for $1-4 \%$ of all primary bone carcinoma and $20 \%$ of spinal tumors (2). Chordoma can occur in any part of the spine; the sacrococcygeal region and skull base are the most common locations, accounting for $\sim 50$ and $30 \%$ of total cases, respectively $(3,4)$. Surgical excision currently remains the first-line therapy, and there is no consensus concerning the effect of adjuvant radiotherapy after surgical treatment; the efficacy of chemotherapy remains controversial due to reported resistance to radiation and chemotherapy (5). Over previous decades, an increasing number of studies have revealed potential genes associated with chordoma, indicating that gene targeted therapy may be an avenue for treating chordoma. For examples, T-box transcription factor T (also known as brachyury) is considered to be the most important gene for chordoma; brachyury is upregulated in chordoma, whilst its expression in normal tissues or other cancers is relatively low (6). Additionally, it has been reported that, to a certain extent, treatments targeting EGFR may therapeutic effects in patients with chordoma $(7,8)$. However, due to a lack of specific drugs for chordoma, further specific and effective potential targets are under investigation.

Transmembrane Emp24 protein transport domain containing 3 (TMED3) is a member of the p24 protein family that serves an important role in the vesicular trafficking of proteins at the secretory endoplasmic reticulum (ER)-Golgi 
interface, and is involved in different signaling pathways in eukaryotic cells $(9,10)$. It has been determined that the p24 protein family contains 10 TMED proteins, of which some serve roles as regulators in the progression of different carcinomas (11). For example, TMED3 plays a prognostic role in clear cell renal cell carcinoma, and is proposed to be a target gene to inhibit the progression of breast cancer, hepatocellular carcinoma, prostate cancer and gastric cancer (12-16). Notably, Mishra et al (17) reported that TMED3 knockdown promoted the lung metastasis of colon cancer in mice, accompanied by the upregulation of TMED9 but downregulation of other TMED proteins, particularly TMED7. Duquet et al (18) demonstrated that knockdown of TMED3 induced lung metastases from HT29 colon cancer cells in vivo, suggesting that TMED3 may serve as a suppressor of colon cancer metastasis. However, the function of TMED3 remains poorly understood, and there is so far no evidence concerning TMED3 in relation to chordoma.

The present study investigated for the first time, to the best of the authors' knowledge, the expression of TMED3 in chordoma cells and the effects of TMED3 knockdown on chordoma development both in vitro and in vivo. Moreover, differentially expressed genes associated with TMED3 in chordoma cells were explored, revealing the potential of TMED3 as a novel target of chordoma therapy (Fig. S1).

\section{Materials and methods}

Cell lines and cell culture. Two human chordoma cell lines were used: MUG-Chor1 (cat. no. CRL-3219) and U-CH1 (cat. no. CRL-3217; both American Type Culture Collection). Cells were cultured in high-glucose DMEM (cat. no. 10-013-CVR; Corning, Inc.) supplemented with $10 \%$ fetal bovine serum (FBS; cat. no. VS500T; Ausbian; Beijing Vian-Saga Biological Technology, Ltd.) and 1\% penicillin-streptomycin stock solution in a humidified cell incubator with $5 \% \mathrm{CO}_{2}$ at $37^{\circ} \mathrm{C}$. Complete growth medium was renewed every 2-3 days and subculture were performed when cells were $80-90 \%$ confluent. All cell function experiments were performed in three parallel biological replicates per group.

Vector construction and lentivirus transduction. For the construction of plasmid vectors, the TMED3 gene sequence (gene accession no. NM_007364) was found in the GenBank database (https://www.ncbi.nlm.nih. gov/nuccore/NM_007364.3). Based on the principles of RNA interference, a target sequence was designed (5'-CTCTCACAA GACCGTCTACTT-3'). Restriction enzyme sites at both ends were added. Additionally, a transcription termination signal TTTTT sequence was added to the $3^{\prime}$ end of the sense strand and a complementary termination signal sequence was added to the 5' end of the antisense strand. Then, the single-stranded DNA oligonucleotides were synthesized (Sangon Biotech Co., Ltd.). According to the manufacturer's protocol, the inverted single-strand DNA oligonucleotide was converted into double DNA strands with cohesive ends after annealing. Then, the plasmid vector BR-V108 with green fluorescent protein (Shanghai Biosciences Co., Ltd.) was linearized under the action of AgeI (cat. no. R3552L) and EcoRI (cat. no. R3101L;
New England Biolabs, Inc.) restriction endonucleases. A BR-V108-short hairpin (sh)RNA vector was constructed after connecting the linearized vector to shRNA using T4 DNA Ligase (cat. no. EL0016; Fermentas; Thermo Fisher Scientific, Inc.), and was transformed and cloned into TOP10 competent E. coli cells (cat. no. CB104-03; Tiangen Biotech Co., Ltd.). A vector containing a non-specific target sequence (5'-TTC TCCGAACGTGTCACGT-3') was used as the negative control (shCtrl). Moreover, PCR was performed to identify the vector. The primer sequences used for PCR amplification were as follows: shTMED3 forward, 5'-CCTATTTCCCATGATTCC TTCATA-3' and reverse, 5'-GTAATACGGTTATCCACG CG-3'; and shCtrl forward, 5'-CCATGATTCCTTCATATT TGC-3' and reverse, 5'-GTAATACGGTTATCCACGCG-3'. Taq Plus DNA Polymerase (cat. no. P201-03; Vazyme Biotech Co., Ltd.) was used and PCR was conducted as follows: $94^{\circ} \mathrm{C}$ for $3 \mathrm{~min}$, followed by 22 cycles of denaturation at $94^{\circ} \mathrm{C}$ for $30 \mathrm{sec}$, annealing at $55^{\circ} \mathrm{C}$ for $30 \mathrm{sec}$ and extension at $72^{\circ} \mathrm{C}$ for $30 \mathrm{sec}$; and a final extension at $72^{\circ} \mathrm{C}$ for $5 \mathrm{~min}$.

The recombinant vectors were extracted according to the instructions of the EndoFree Maxi Plasmid kit (cat. no. DP117; Tiangen Biotech Co., Ltd.). 293T cells were seeded on a $100-\mathrm{mm}$ plate $\left(\sim 5 \times 10^{6}\right.$ cells/well; Shanghai Biosciences Co., Ltd.) until $80 \%$ confluent and then co-transfected with recombinant vectors $(20 \mu \mathrm{g})$, pHelper 1.0 vector $(15 \mu \mathrm{g})$ and pHelper 2.0 vector $(10 \mu \mathrm{g}$; all Shanghai Biosciences Co., Ltd.) using transfection reagent (Lipofectamine ${ }^{\mathrm{TM}}$ 3000; Invitrogen; Thermo Fisher Scientific, Inc.). After transfecting for $48 \mathrm{~h}$, lentiviral vectors (LV-shTMED3 and LV-shCtrl) were separated and purified. Chordoma cells were seeded on 6-well plates $\left(\sim 1 \times 10^{5}\right.$ cells/well) and transfected with lentivirus using polybrene (6 $\mu \mathrm{g} / \mathrm{ml}$; cat. no. TR-1003-G; Sigma-Aldrich; Merck $\mathrm{KGaA}$ ) according to the specific multiplicity of infection $(\mathrm{MOI}=10)$. After lentiviral transduction for $72 \mathrm{~h}$, reverse transcription-quantitative (RT-q) PCR and western blot analyses were performed in order to evaluate the expression of TMED3, and the fluorescence of cells were detected using an inverted fluorescence microscope.

$R T-q P C R$. A two-step RT-qPCR protocol was performed to quantify the expression of TMED3 in lentivirus-transfected cells and normal chordoma cells. Chordoma cells were seeded on 6-well plates until $80-90 \%$ confluent. Total RNA from cells was collected using TRIzol ${ }^{\circledR}$ reagent (cat. no. 15596018; Invitrogen; Thermo Fisher Scientific, Inc.) and a spectrophotometer (NanoDrop ${ }^{\mathrm{TM}}$ 2000; Thermo Fisher Scientific, Inc.) was used to measure and calculate the RNA concentration of samples. RT was performed according to the protocols of the HiScript Reverse Transcriptase kit (cat. no. R123-01; Vazyme Biotech Co., Ltd.): A reaction mixture that contained chordoma cell RNA ( $2 \mu \mathrm{g})$ was prepared and first incubated at $42^{\circ} \mathrm{C}$ for $2 \mathrm{~min}$ before reacting at $50^{\circ} \mathrm{C}$ for $15 \mathrm{~min}$ and $85^{\circ} \mathrm{C}$ for $2 \mathrm{~min}$. qPCR was performed as recommended by the AceQ SYBR Green kit protocols (cat. no. Q111-02; Vazyme Biotech Co., Ltd.). The primer sequences were as follows: TMED3 forward, 5'-GGCGTGAAGTTCTCCCTGGATT-3' and reverse, 5'-GCTGTCGTACTGCTTCTTCGTTTC-3'; and GAPDH forward, 5'-CGGATTTGGTCGTATTGGG-3' and reverse, 5'-GATTTTGGAGGGATCTCGC-3'. qPCR was conducted as follows: $95^{\circ} \mathrm{C}$ for $5 \mathrm{~min}$, followed by 40 cycles 
of denaturation at $95^{\circ} \mathrm{C}$ for $30 \mathrm{sec}$, annealing at $58^{\circ} \mathrm{C}$ for $30 \mathrm{sec}$ and extension at $72^{\circ} \mathrm{C}$ for $45 \mathrm{sec}$; and a final extension at $72^{\circ} \mathrm{C}$ for $7 \mathrm{~min}$. qPCR data were analyzed using the $2^{-\Delta \Delta \mathrm{Cq}}$ method $(19,20)$; after normalization to the reference gene, relative gene expression levels were calculated by comparing with the control group.

Western blot analysis. Western blotting was performed to examine the expression of proteins in U-CH1 and MUG-Chor1 chordoma cells under different conditions. Cells were seeded on 6-well plates. When cells were $80-90 \%$ confluent, cells were lysed using RIPA buffer (cat. no. P0013B; Beyotime Institute of Biotechnology) containing 1\% PMSF (cat. no. ST506; Beyotime Institute of Biotechnology) and deacetylase inhibitor cocktail (cat. no. P1112; Beyotime Institute of Biotechnology) and the supernatant was collected after centrifugation at 13,200 x g for $10 \mathrm{~min}$ at $4^{\circ} \mathrm{C}$. Using a Pierce ${ }^{\mathrm{TM}}$ BCA Protein Assay kit (cat. no. 23235; Thermo Fisher Scientific, Inc.), protein samples were diluted and the absorbance was measured at $562 \mathrm{~nm}$. A standard curve was prepared and the concentration of each lysate sample was determined. Equal quantities of protein samples $(20 \mu \mathrm{g})$ and PageRuler ${ }^{\mathrm{TM}}$ protein marker (cat. no. 26617; Thermo Fisher Scientific, Inc.) were loaded and separated via $12 \%$ SDS-PAGE. Protein blots were transferred to PVDF membrane (cat. no. 88585; Thermo Fisher Scientific, Inc.) and blocked in TBS- $0.05 \%$ Tween 20 (TBST) containing 5\% skim milk at room temperature for $1 \mathrm{~h}$. The membranes were incubated with the following primary antibodies overnight at $4^{\circ} \mathrm{C}$ : Rabbit anti-TMED3 (1:2,000; cat. no. ab223175; Abcam); rabbit anti-GAPDH (1:3,000; cat. no. AP0063; Bioworld Technology, Inc.); rabbit anti-Akt (1:1,000; cat. no. 4685; Cell Signaling Technology, Inc.); rabbit anti-phosphorylated (p)-Akt antibody (1:1,000; cat. no. bs-5193r; BIOSS); rabbit anti-cyclin D1 (1:2,000; cat. no. 2978; Cell Signaling Technology, Inc.); rabbit anti-CDK6 (1:1,000; cat. no. ab151247; Abcam); and rabbit anti-MAPK9 (1:1,000; cat.no. ab76125; Abcam). The membranes were washed, followed by incubation with horseradish peroxidase-conjugated goat anti-rabbit secondary antibody $(1: 3,000$; cat. no. A0208; Beyotime Institute of Biotechnology) for $1 \mathrm{~h}$ at room temperature. Chemiluminescent analysis was performed using Immobilon Western Chemiluminescent HRP substrate (cat. no. WBKLS0050; EMD Millipore). GAPDH protein was used as the internal reference.

Cell apoptosis analysis. Cell apoptosis was analyzed using an Annexin V-allophycocyanin (APC) Apoptosis Detection kit (cat. no. 88-8007-74; eBioscience; Thermo Fisher Scientific, Inc.), chordoma cells were seeded on 6 -well plates until $80 \%$ confluent. The supernatant was discarded and cells were washed using PBS buffer. After digestion, the cell suspension was collected, followed by centrifugation at 1,050 $\mathrm{x} g$ for $5 \mathrm{~min}$ at $4^{\circ} \mathrm{C}$ and washing using $1 \mathrm{X}$ binding buffer. Cells were resuspended in $1 \mathrm{X}$ binding buffer $(200 \mu \mathrm{l})$ at $1-5 \times 10^{6} / \mathrm{ml}$. Then, $10 \mu \mathrm{l}$ Annexin V-APC was mixed with the cell suspension, which was incubated in dark for $10 \mathrm{~min}$ at room temperature. Fluorescence-activated cell sorting (FACS) analysis was performed using a flow cytometer (Guava easyCyte HT; EMD Millipore) and InCyte 3.1 software (EMD Millipore) to detect the fluorescence of GFP and Annexin V-APC of the stained cells. The apoptosis rate was calculated according to the scatter diagram of apoptosis. Apoptosis rate=rate of upper right quadrant + rate of lower right quadrant.

MTT assay. To detect the viability of U-CH1 and MUG-Chor1 chordoma cells, an MTT assay was performed. Cells were seeded on a 96-well plate $(2,000$ cells/well) and cultured for $1-5$ days at $37^{\circ} \mathrm{C}$. Then, MTT $(5 \mathrm{mg} / \mathrm{ml}$; cat. no. JT343; Gen-View Scientific, Inc.) was added to each well and cells were cultured for $4 \mathrm{~h}$. Subsequently, medium was discarded and $100 \mu \mathrm{l}$ DMSO were added. The optical density of each well at 490/570 nm was measured; results were analyzed after data were collected for 5 days.

Wound healing assay. Cells in the exponential growth phase were cultured until $>90 \%$ confluent on a 96-well plate $\left(\sim 3 \times 10^{4}\right.$ cells/well $)$ in DMEM containing $10 \% \mathrm{FBS}$. The medium was then discarded and a 96 Wounding Replicator (V\&P Scientific) was used to make a straight scratch across the cells, after which the cells were washed and subsequently cultured with low-serum medium $(0.5 \%$ FBS $)$. Using the width of the scratch after culturing at $37^{\circ} \mathrm{C}$ with $5 \% \mathrm{CO}_{2}$ for 0,24 and $48 \mathrm{~h}$, the migration rate of each group was calculated: Migration rate $=[$ width $(0 \mathrm{~h})$-width $(24$ or $48 \mathrm{~h})]$ /width $(0 \mathrm{~h})$.

Transwell assay. Chambers were put in a 24-well plate. Serum-free medium $(100 \mu \mathrm{l})$ was prepared and added to the chamber for incubation for $1-2 \mathrm{~h}$ at $37^{\circ} \mathrm{C}$, after which the medium was replaced and cells were added $\left(1-2 \times 10^{5} / \mathrm{ml}\right.$ in serum-free medium), while $600 \mu 1$ DMEM (with 30\% FBS) was added to the lower chamber. The chambers were cultured for $24 \mathrm{~h}$ at $37^{\circ} \mathrm{C}$. Migrated cells were then fixed using $4 \%$ paraformaldehyde for $20 \mathrm{~min}$ at room temperature and were stained using Giemsa for $15 \mathrm{~min}$ at room temperature while non-migrated cells were scraped off. A high-power light microscope was used and the number of migrated cells in five fields/well was counted (magnification, x200).

Cell cycle assay. Cells in the exponential growth phase were cultured on a $6-\mathrm{cm}$ dish in DMEM containing $10 \%$ FBS at $37^{\circ} \mathrm{C}$ for $24 \mathrm{~h}$. Cells at $80 \%$ confluence were resuspended in PBS buffer and fixed in $70 \%$ precooled ethanol overnight at $4^{\circ} \mathrm{C}$. After centrifugation at $1,400 \mathrm{x}$ g for $5 \mathrm{~min}$ at $4^{\circ} \mathrm{C}$ and resuspension, cells $\left(1-6 \times 10^{6} / \mathrm{ml}\right)$ were collected again and incubated with RNase (100 $\mu \mathrm{g} / \mathrm{ml}$; cat. no. 2158-1; Takara Bio, Inc.) and PI (50 $\mu \mathrm{g} / \mathrm{ml}$; cat. no. P4170; Sigma-Aldrich; Merck $\mathrm{KGaA}$ ) at room temperature for $30 \mathrm{~min}$ in the dark. Finally, FACS analysis was performed using a flow cytometer (Guava easyCyte HT) and ModFit LT 3.3 software (Verity Software House) to determine the DNA content of cells.

Tumor xenograft model. A total of 10 female BALB/c nude mice (age, 4 weeks; weight, 15.5-17.5 g) were obtained from Shanghai Laboratory Animal Center and maintained in a standard 12:12-h light/dark cycle under temperature (20-22 $\left.{ }^{\circ} \mathrm{C}\right)$ and humidity (40-60\%)-controlled conditions with ad libitum access to food and water. MUG-Chor1 chordoma cells were infected with the shRNA lentivirus as described above, digested with trypsin and resuspended. Chordoma cell suspensions $\left(200 \mu \mathrm{l} ; 1 \times 10^{7}\right.$ cells/ml) from the shTMED3 and shCtrl groups were injected subcutaneously into the 
A

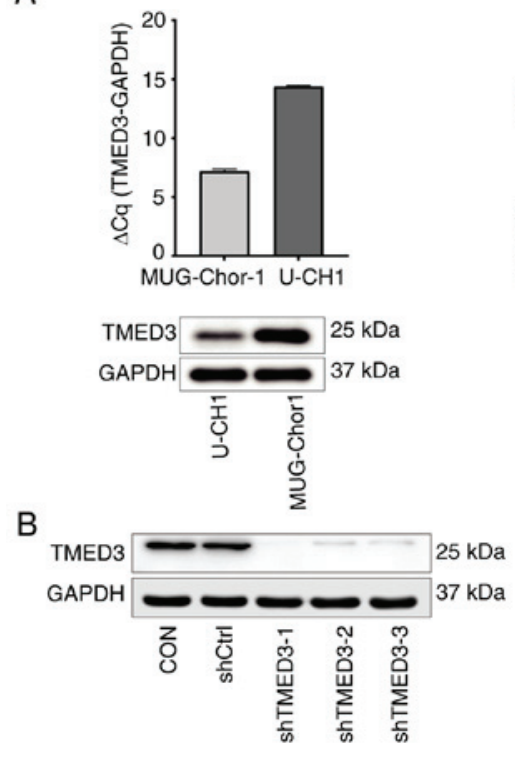

$\mathrm{C}$
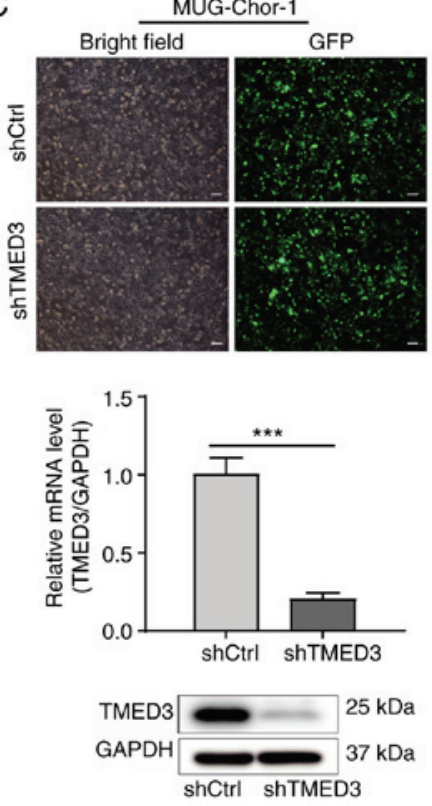
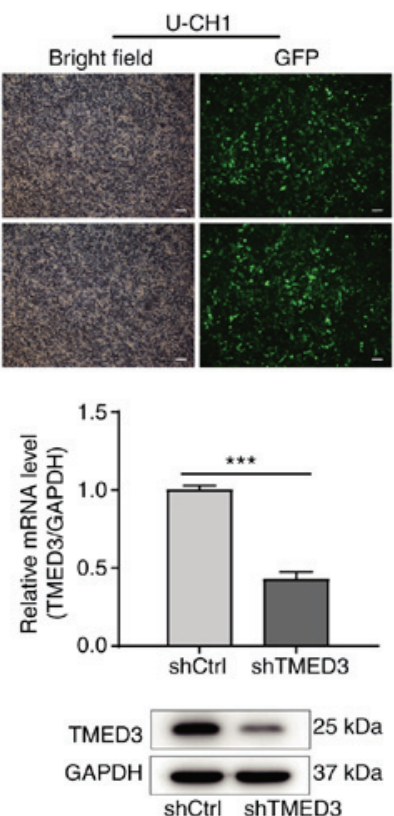

Figure 1. TMED3 is highly expressed in chordoma and knocked down following lentiviral transduction. (A) Expression of TMED3 was detected in MUG-Chor1 and U-CH1 cells via RT-qPCR analysis according to the $\mathrm{Cq}$ value $\left(\Delta \mathrm{Cq}=\mathrm{Cq}_{\mathrm{TMED}}-\mathrm{Cq}_{\mathrm{GAPDH}}\right)$, as well as via western blot analysis. Expression was normalized to GAPDH. (B) Efficacy of lentiviral infection of chordoma cells using different shTMED3 sequences was detected via western blot analysis. Cells in the CON group were not exposed to any lentivirus. (C) Efficiency of lentiviral transfection was detected according to the fluorescence intensity after transfection for $72 \mathrm{~h}$, as well as via western blot and RT-qPCR analyses. ${ }^{* * *} \mathrm{P}<0.001$. Expression was normalized to GAPDH. Scale bar, 200 $\mu \mathrm{m}$. TMED3, transmembrane Emp24 protein transport domain containing 3; sh, short hairpin (RNA); shCtrl, negative control shRNA; RT-qPCR, reverse transcription-quantitative PCR; Cq, quantification cycle.

armpits of the right forelimbs of mice. At 5-7 days later, the dimensions of tumors were measured using a Vernier caliper and the tumor volume in $\mathrm{mm}^{3}$ was calculated according to the following formula: $\mathrm{V}=\pi / 6 \times \mathrm{L} \times \mathrm{W} \times \mathrm{W}$, where $\mathrm{V}$ is the tumor volume, $\mathrm{L}$ is the long tumor diameter and $\mathrm{W}$ is the short tumor diameter. At 33 days after subcutaneous injection, mice with tumor xenografts were anesthetized via intraperitoneal injection of $0.7 \%$ pentobarbital $(70 \mathrm{mg} / \mathrm{kg})$ and tumors were detected using an in vivo fluorescence imaging scanner. Fluorescence intensity was detected by the system due to green fluorescent protein expression in the cells. Mice were sacrificed and tumors were obtained for weight measurements and subsequent H\&E analysis. Humane endpoints were reached when the xenograft tumor reached $>10 \%$ of the animal's body weight, the tumor diameter was $>20 \mathrm{~mm}$, tumors metastasized or grew such that it led to rapid body weight loss ( $>20 \%$ ), or signs of immobility, a huddled posture, the inability to eat, ruffled fur, self-mutilation, ulceration, infection or necrosis were observed. Animals that reached study endpoints were euthanized via cervical dislocation under anesthesia following intraperitoneal injection of pentobarbital $(70 \mathrm{mg} / \mathrm{kg})(21)$. Death was verified by the cessation of a heartbeat and dilated pupils.

The present study was conducted according to the Guide for the Care and Use of Laboratory Animals of the National Institutes of Health (22) and approved by the Animal Ethics Committee of Zhujiang Hospital of Southern Medical University (approval no. IACUC-2019010).

$H \& E$ and immunohistochemistry (IHC) staining. To gain further insight into the effects of TMED3 on tumor progression, isolated tumor masses underwent fixation in $10 \%$ formaldehyde at room temperature for $24 \mathrm{~h}$ and tissue dehydration, and were subsequently embedded in paraffin, followed by cutting into $4-\mu \mathrm{m}$ sections and histological analysis. Tissue was stained by hematoxylin (cat. no. BA4041; BaSO Biotech) and eosin (cat. no. BA4022; BaSO Biotech) for $3 \mathrm{~min}$ and $8 \mathrm{sec}$, respectively, at room temperature. Light microscope was used to visualize cell patterns. IHC analysis was performed to verify the expression of specific gene. Briefly, after dewaxing and rehydration, sections were incubated in citrate buffer ( $\mathrm{pH} \mathrm{6.0)}$ and microwaved for $10 \mathrm{~min}$. Sections were then cooled down to room temperature and incubated in peroxidase block $\left(3 \% \mathrm{H}_{2} \mathrm{O}_{2}\right)$ for $5 \mathrm{~min}$ at room temperature. Sections were then incubated in $5 \%$ normal goat serum (cat. no. C01-03001; BIOSS) for $5 \mathrm{~min}$ at room temperature. Animal tissue was stained using rabbit anti-Ki67 antibody (1:200; cat. no. ab16667; Abcam) overnight at $4^{\circ} \mathrm{C}$ and horseradish peroxidase-conjugated goat anti-rabbit antibody (1:400; cat. no. ab6721; Abcam) for $30 \mathrm{~min}$ at $37^{\circ} \mathrm{C}$ in order to determine differences between tumor cells in shTMED3 and shCtrl tissues. Expression was visualized using 3,3'-diaminobenzidine (cat. no. ab64238; Abcam), and nuclei were counterstained using hematoxylin for $10 \mathrm{sec}$ at room temperature. A light microscope was used to observe sections (magnification, x100 and x200) and five fields of each section were analyzed.

Clinical specimens of chordoma and para-carcinoma tissue were collected. and preliminary validation was performed to identify the expression of TMED3 via IHC. A total of 5 patients with histologically confirmed chordoma were included in the study. Specimens from patients that 


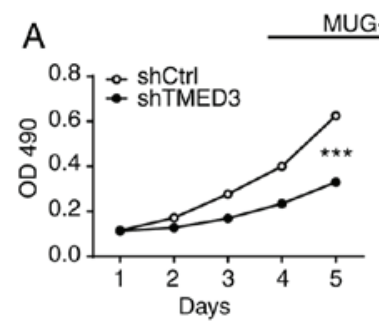

MUG-Chor1

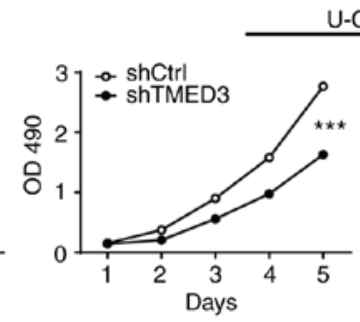

\section{$\mathrm{U}-\mathrm{CH} 1$}
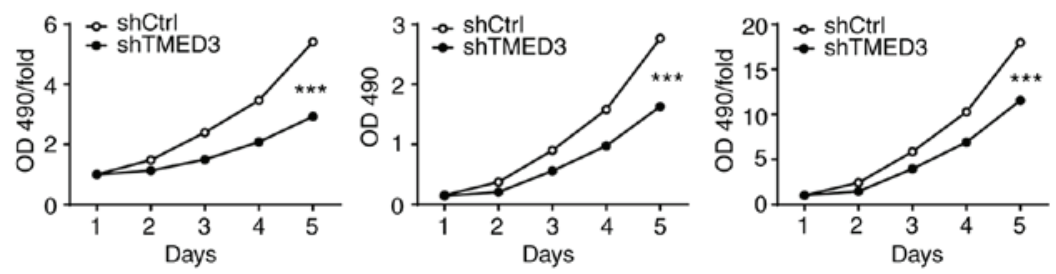

B
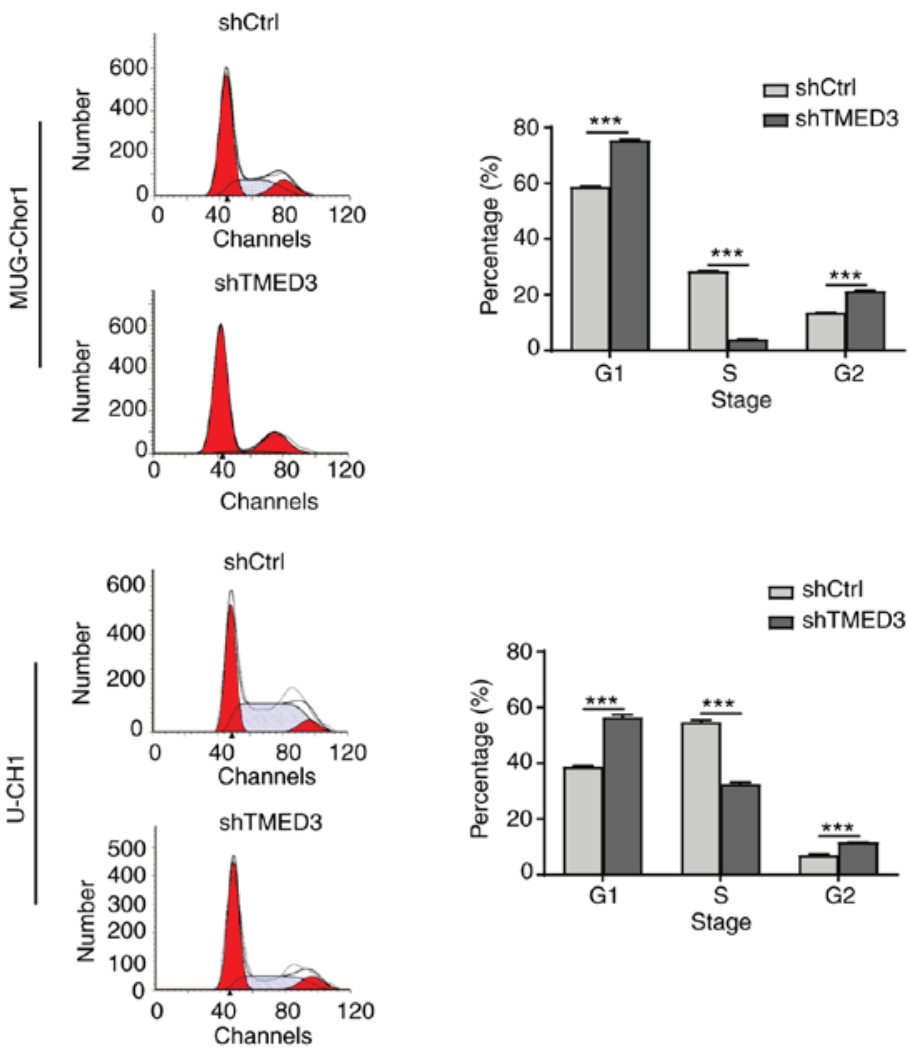

Figure 2. Knockdown of TMED3 inhibits chordoma cell proliferation. (A) Cell proliferation ability of MUG-Chor1 and U-CH1 cells was detected using an MTT array. The OD value at $490 \mathrm{~nm}$ of each well was measured after cell culture for 1-5 days. (B) Fluorescence-activated cell sorting analysis was performed to determine the effects of TMED3 on the cell cycle progression of MUG-Chor1 and U-CH1 cells; the proportions of cells in G1, S and G2 phases were detected. ${ }^{* * *} \mathrm{P}<0.001$ vs. shCtrl. TMED3, transmembrane Emp24 protein transport domain containing 3; sh, short hairpin (RNA); shCtrl, negative control shRNA; OD, optical density.

received surgical resection for chordoma between April 2018 and June 2020 were stored in the Pathology Department of Zhujiang Hospital of Southern Medical University and used for IHC. All patients were male and ranged in age (37-57 years). Of the 5 chordoma cases, 2 originated from the sacrum and 3 from the skull base. Human experiments were approved by the Ethics Review Committee of the Zhujiang Hospital of Southern Medical University (approval no. 2020-KY-030-01), and written consent was provided by patients. Sections were stained using anti-TMED3 antibody (1:50; cat. no. ab151056; Abcam), an UltraSensitive ${ }^{\mathrm{TM}}$ SP (Mouse/Rabbit) IHC kit (cat. no. KIT-9710; MXB Biotechnologies) and hematoxylin. IHC analysis was conducted according to the procedure mentioned above.

Human apoptosis antibody array. According to the manufacturer's protocols for a Human Apoptosis Antibody Array kit (cat. no. ab134001; Abcam), 43 human apoptosis markers were detected in cells simultaneously. Analysis was performed using ImageJ 1.5 software (National Institutes of Health) to detect the signal density of each spot, followed by normalization to the positive control spot signals.

Statistical analysis. All statistical analysis was performed using GraphPad Prism 8 software (GraphPad Software, Inc.). Data are presented as the mean \pm SD. Data were analyzed using Student's t-test when comparing two groups. $\mathrm{P}<0.05$ was considered to indicate a statistically significant difference.

\section{Results}

TMED3 is highly expressed in chordoma and downregulated by lentiviral infection. Chordoma tissues from patients were used in the present study for preliminary analysis of TMED3 expression. All chordoma specimens exhibited similar microscopic characteristics (chordal-arranged, vacuolated and eosinophilic cells with intra- and extracellular mucus). Moreover, postoperative analysis revealed positive staining for cytokeratin, mucin-1, S-100 and vimentin; Ki67 staining was $1-10 \%$ positive. IHC staining revealed that TMED3 was 

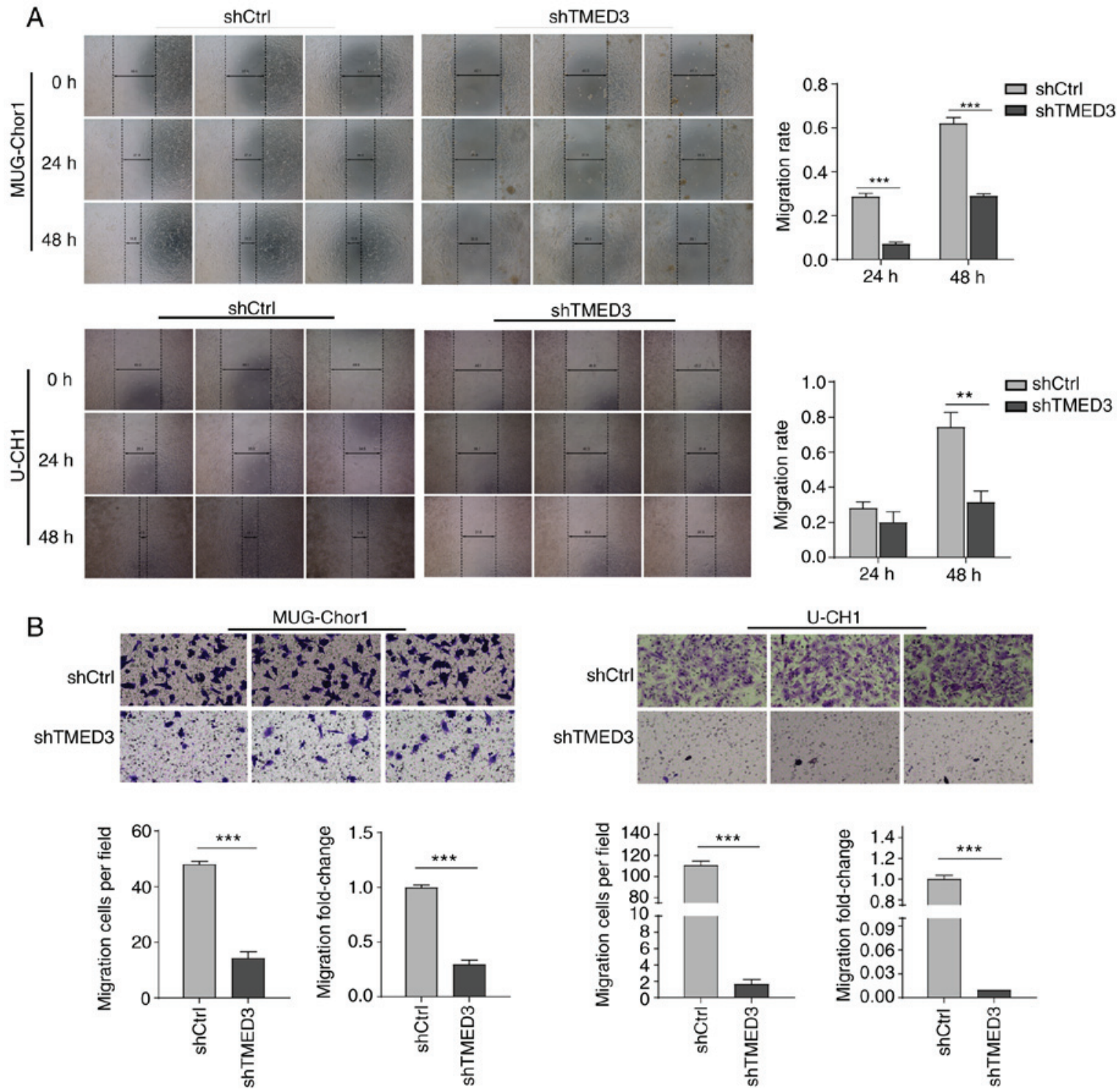

Figure 3. Knockdown of TMED3 inhibits chordoma cell migration. (A) Cell migration ability of MUG-Chor1 and U-CH1 cells was determined via a wound healing assay. The widths of scratches were detected following culture for 0,24 and $48 \mathrm{~h}$, and the migration rate of each group was calculated. ${ }^{* *} \mathrm{P}<0.01$, ${ }^{* * *} \mathrm{P}<0.001$. (B) Transwell assays were performed to further evaluate the migration abilities of MUG-Chorl and U-CH1 cells. After culture for $24 \mathrm{~h}$, migrated cells were counted under a high-power light microscope (magnification, x200) and the migration rate was calculated. ${ }^{* * *} \mathrm{P}<0.001$. TMED3, transmembrane Emp24 protein transport domain containing 3; sh, short hairpin (RNA); shCtrl, negative control shRNA.

primarily distributed in the cytoplasm of cells in chordoma tissues (Fig. S2). In U-CH1 and MUG-Chor1 chordoma cell lines, RT-qPCR analysis suggested that the expression of TMED3 was high in MUG-Chorl cells $(\triangle \mathrm{Cq}=7.21)$, while there was moderate expression in $\mathrm{U}-\mathrm{CH} 1$ cells $(\Delta \mathrm{Cq}=14.4$; Fig. $1 \mathrm{~A})$. Western blot analysis revealed that, compared with the shCtrl group, the protein levels of TMED3 in cells infected with shTMED3-1, shTMED3-2 and shTMED3-3 were downregulated; as shTMED3-1 exhibited the strongest efficacy, this was selected as the shRNA for subsequent experiments (Fig. 1B). After lentiviral transduction for $72 \mathrm{~h}$, the fluorescence of cells infected with LV-shCtrl or LV-shTMED3 indicated $>80 \%$ efficiency of infection. Additionally, it was demonstrated via RT-qPCR and western blot analyses that TMED3 was significantly downregulated in the shTMED3 group compared with the shCtrl group (Fig. 1C). Collectively, it was indicated that TMED3 was positively expressed in MUG-Chor1 and U-CH1 chordoma cell lines, and that the lentiviral knockdown was successful.

Knockdown of TMED3 inhibits chordoma cell viability and migration. In order to obtain insight into the function of TMED3 in chordoma cells in vitro, the effects of TMED3 knockdown on cell viability and migration were detected. MTT assays showed that, compared with the shCtrl group, cells in the shTMED3 group exhibited significantly reduced viability in the MUG-Chor1 [fold change $(\mathrm{FC})=-1.85$, $\mathrm{P}<0.001]$ and $\mathrm{U}-\mathrm{CH} 1$ cell lines $(\mathrm{FC}=-1.56, \mathrm{P}<0.001$; Fig. $2 \mathrm{~A})$. Furthermore, FACS analysis was performed to investigate the cell cycle in chordoma. Compared with shCtrl, the percentage of cells in G1 and G2 phase was increased in the shTMED3 group, whereas the percentage of cells in $\mathrm{S}$ phase decreased in the MUG-Chorl (G1, 75.12 \pm 0.66 vs. 58.52 \pm 0.46 , $\mathrm{P}<0.001 ; \mathrm{G} 2,21.10 \pm 0.38$ vs. $13.38 \pm 0.20, \mathrm{P}<0.001 ; \mathrm{S}$, 

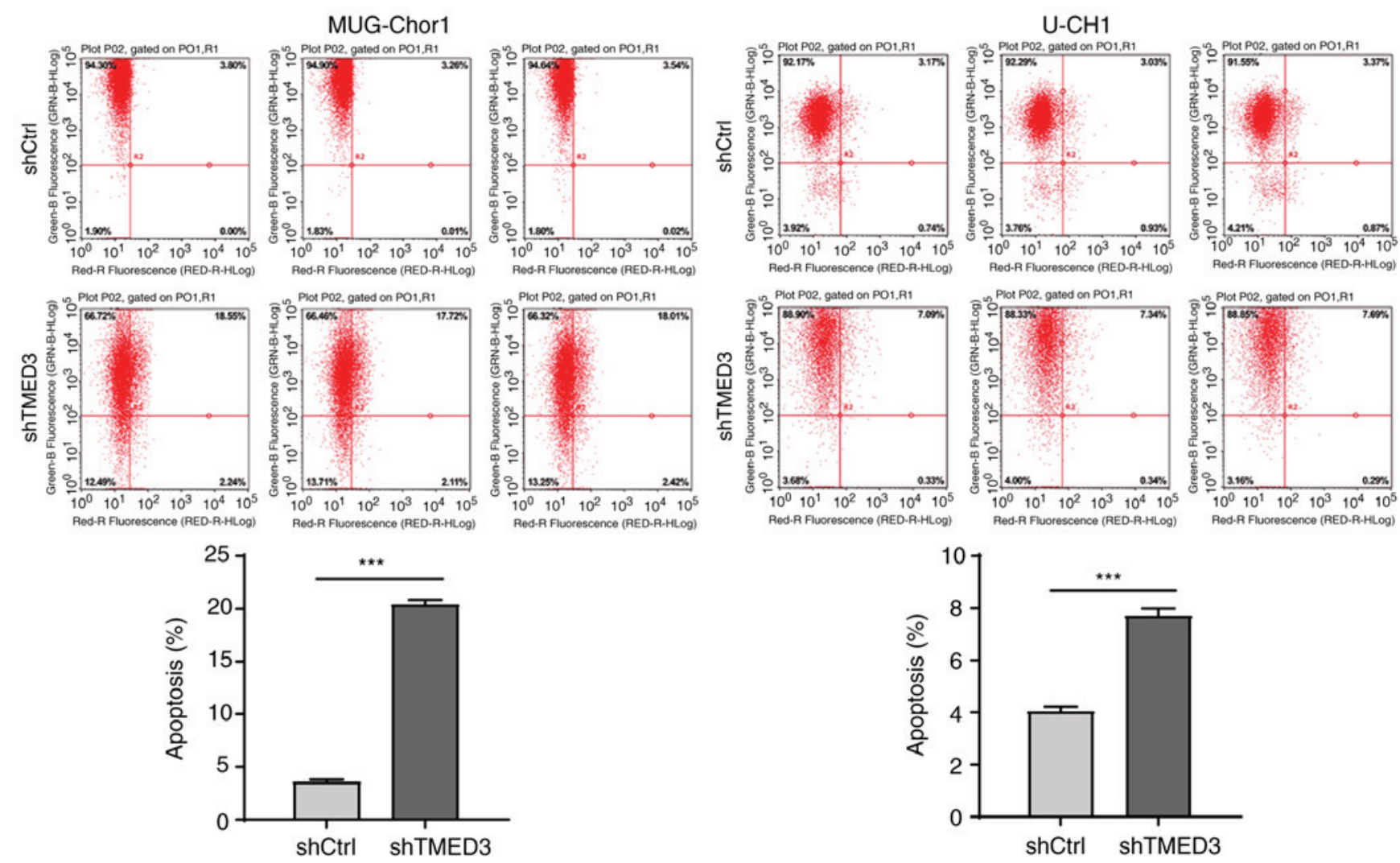

Figure 4. Knockdown of TMED3 increases chordoma cell apoptosis. Fluorescence-activated cell sorting analysis was performed to identify the effects of TMED3 in the apoptosis of MUG-Chorl and U-CH1 cells; the proportion of apoptotic cells was detected when cells were at $85 \%$ confluence following lentiviral transfection. ${ }^{* * * *} \mathrm{P}<0.001$. TMED3, transmembrane Emp24 protein transport domain containing 3; sh, short hairpin (RNA); shCtrl, negative control shRNA.

$3.78 \pm 0.28$ vs. $28.14 \pm 0.40, \mathrm{P}<0.001)$ and $\mathrm{U}-\mathrm{CH} 1$ cell lines (G1, 56.26 \pm 1.16 vs. $38.48 \pm 0.63, \mathrm{P}<0.001 ; \mathrm{G} 2,11.47 \pm 0.24$ vs. $7.01 \pm 0.33, \mathrm{P}<0.001 ; \mathrm{S}, 32.27 \pm 0.93$ vs. $54.51 \pm 0.93, \mathrm{P}<0.001$; Fig. 2B). Moreover, wound healing assays revealed that the average cell migration rate in the shTMED3 group compared with the shCtrl group was decreased both in MUG-Chor1 (24 h, $0.07 \pm 0.01$ vs. $0.29 \pm 0.02, \mathrm{P}<0.001 ; 48 \mathrm{~h}, 0.29 \pm 0.01$ vs. $0.62 \pm 0.02, \mathrm{P}<0.001)$ and $\mathrm{U}-\mathrm{CH} 1$ cells $(24 \mathrm{~h}, 0.20 \pm 0.06$ vs. $0.28 \pm 0.03, \mathrm{P}>0.05 ; 48$ h, $0.31 \pm 0.06$ vs. $0.74 \pm 0.08, \mathrm{P}<0.01$; Fig. 3A), indicating that cell migration was suppressed after knockdown of TMED3. Similarly, Transwell assays revealed that the migration of cells in the shTMED3 group compared with shCtrl group was significantly inhibited by $71 \%$ in MUG-Chorl cells $(14 \pm 2.14$ vs. $48 \pm 1.31, \mathrm{P}<0.001)$ and $99 \%$ in $\mathrm{U}-\mathrm{CH} 1$ cells $(1 \pm 0.23$ vs. $111 \pm 4.02, \mathrm{P}<0.001$; Fig. $3 \mathrm{~B})$. The aforementioned analysis suggested that TMED3 is tumor-associated, and that downregulating TMED3 inhibited cell viability and migration in chordoma.

Knockdown of TMED3 increases chordoma cell apoptosis. Next, in order to explore the effects of TMED3 on chordoma cell apoptosis, Annexin V-APC was used to stain chordoma cells; FACS analysis revealed that, compared with the shCtrl group, the apoptosis rate was significantly increased in the shTMED3 group in MUG-Chorl $(20.35 \pm 0.48 \%$ vs. $3.54 \pm 0.27 \%, \mathrm{P}<0.001)$ and U-CH1 cell lines $(7.69 \pm 0.29 \%$ vs. $4.04 \pm 0.18 \%, \mathrm{P}<0.001$; Fig. 4). These results indicated that knockdown of TMED3 promoted chordoma cell apoptosis, and that TMED3 may be associated with chordoma progression via apoptosis signaling pathways.

Knockdown of TMED3 inhibits chordoma growth in vivo. To verify the role of TMED3 in chordoma in vivo, a tumor xenograft model was established by injecting shCtrl- or shTMED3-infected MUG-Chorl chordoma cells subcutaneously into nude mice, followed by measurements of tumor volume and weight. Reductions in average tumor weight were observed in the shTMED3 group compared with the shCtrl group $(0.082 \pm 0.066 \mathrm{~g}$ vs. $0.342 \pm 0.083 \mathrm{~g} ; \mathrm{P}<0.001)$, and the average tumor volume in the shTMED3 group was significantly smaller compared with the shCtrl group (Fig. 5A-F). Furthermore, IHC staining revealed that, compared with the shCtrl group, the shTMED3 group exhibited downregulation of Ki67 expression, which is considered to be a biomarker for tumor growth, further suggesting that TMED3 may be an important contributor to chordoma growth (Fig. 5G).

TMED3 regulates signaling pathways involved in cell cycle, apoptosis and proliferation. To further explore the mechanisms underlying the regulation of chordoma by TMED3, differentially expressed proteins were screened using a human apoptosis marker array and western blot analysis. The results showed that, compared with the shCtrl group, the protein levels of Bcl-2, heat shock protein 27 (HSP27), insulin-like growth factor (IGF)-I, IGF-II, IGF binding protein-2 (IGFBP-2) and Livin were significantly downregulated (reductions in gray 


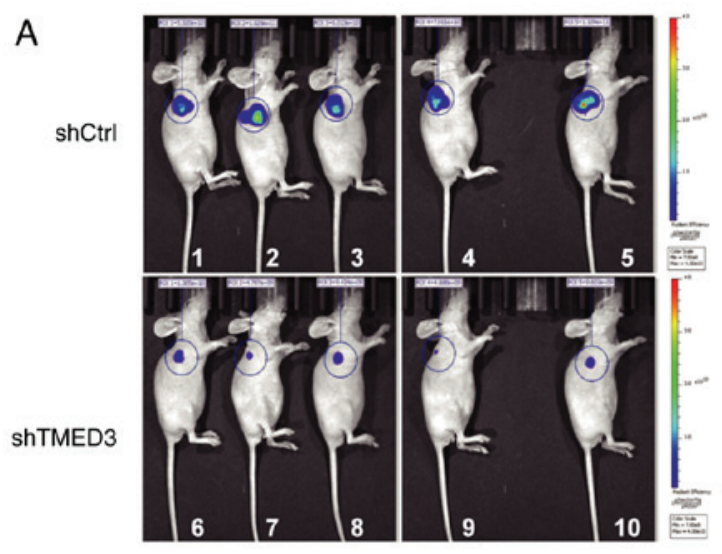

B

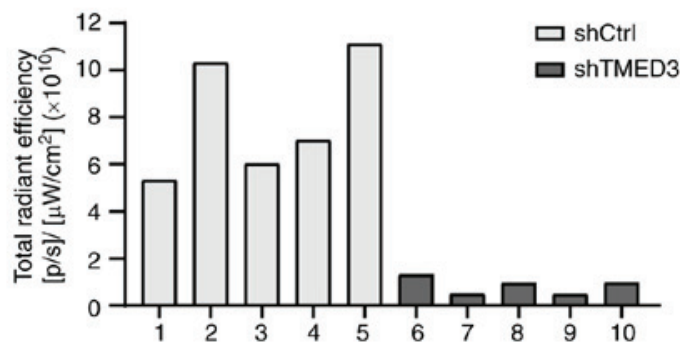

C

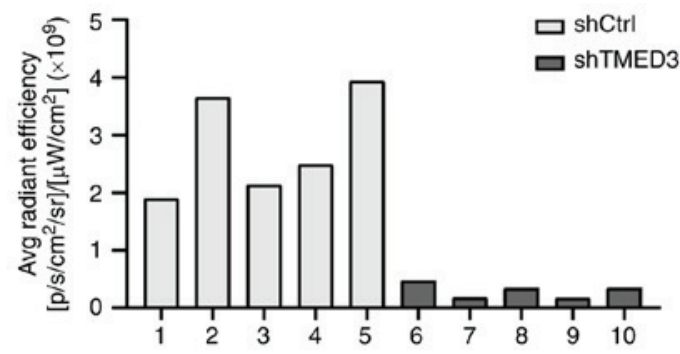

D

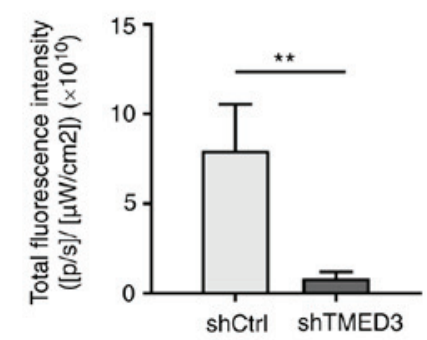

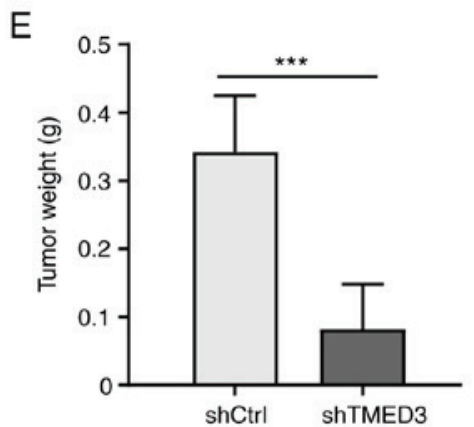

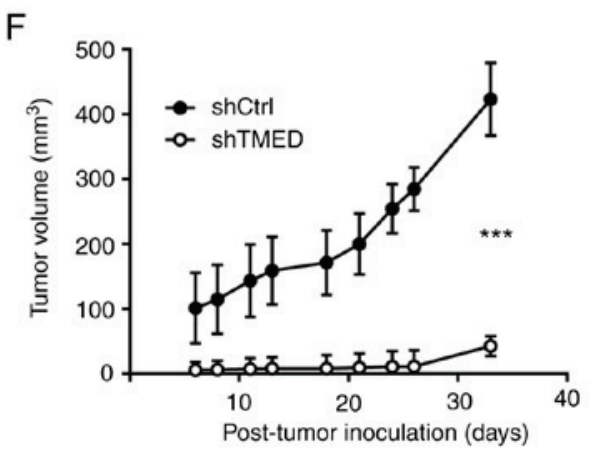

G
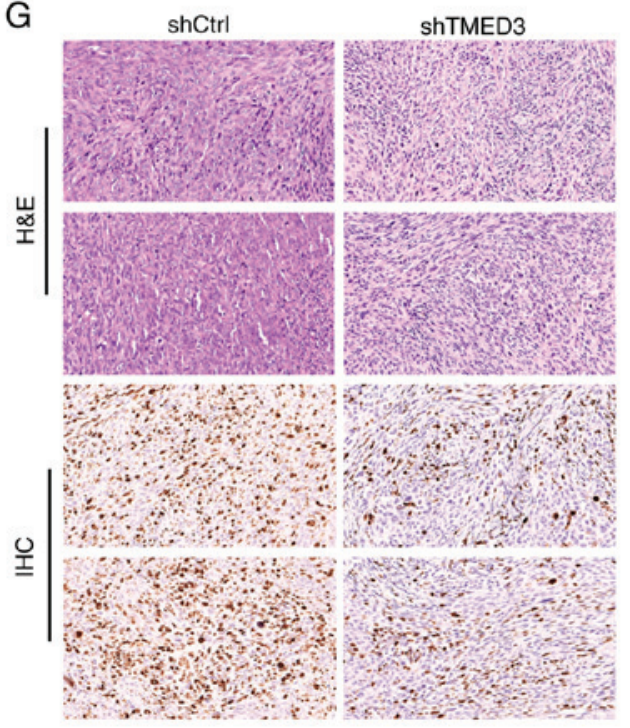

Figure 5. TMED3 promotes chordoma growth in vivo. (A) At 33 days after inoculation, the tumors in 10 nude mice were detected using an in vivo imaging system and the (B) total and (C) average radiant efficiency were measured, as well as the (D) fluorescence intensity. (E) Tumors in 10 nude mice were harvested and measured after euthanasia. (F) After inoculation, the volumes of tumors in mice were calculated. (G) Xenograft tissues from nude mice were harvested and subsequently stained with hematoxylin and eosin or reacted with anti-Ki67 antibody. ${ }^{* *} \mathrm{P}<0.01,{ }^{* * *} \mathrm{P}<0.001$. TMED3, transmembrane Emp24 protein transport domain containing 3; sh, short hairpin (RNA); shCtrl, negative control shRNA.

value of 42.63, 28.48, 23.87, 43.98, 25.81 and $28.91 \%$, respectively, $\mathrm{P}<0.05$; Fig. $6 \mathrm{~A}$ and $\mathrm{B}$ ) among 43 proteins involved in cell apoptosis. In addition, western blot analysis revealed that knockdown of TMED3 resulted in downregulation of Akt, p-Akt, CDK6 and cyclin D1, and upregulation of MAPK9 (Fig. 6C). These results indicated that TMED3 promoted chordoma progression by regulating cell apoptosis-related proteins and Akt signaling (Fig. S3).

\section{Discussion}

Chordoma is a rare bone cancer with limited treatment options; currently, surgical operation is the first-line therapy, but it is difficult to radically excise chordoma tumors (5). Additionally, there is no consensus concerning the effects of radiotherapy and chemotherapy following surgical resection. Due to resistance to traditional therapies, targeted therapy has been considered to be a more effective way to overcome the challenges involved in chordoma treatment. TMED3, a member of the p24 protein family that has been shown to be critically involved in the transportation of secretory cargo from the ER to the Golgi complex $(9,10)$, has been demonstrated to promote cancer progression in recent years, including clear cell renal cell carcinoma, breast cancer and gastric cancer (12-14).

The present study aimed to explore the role served by TMED3 in chordoma. It was found that TMED3 protein 
A
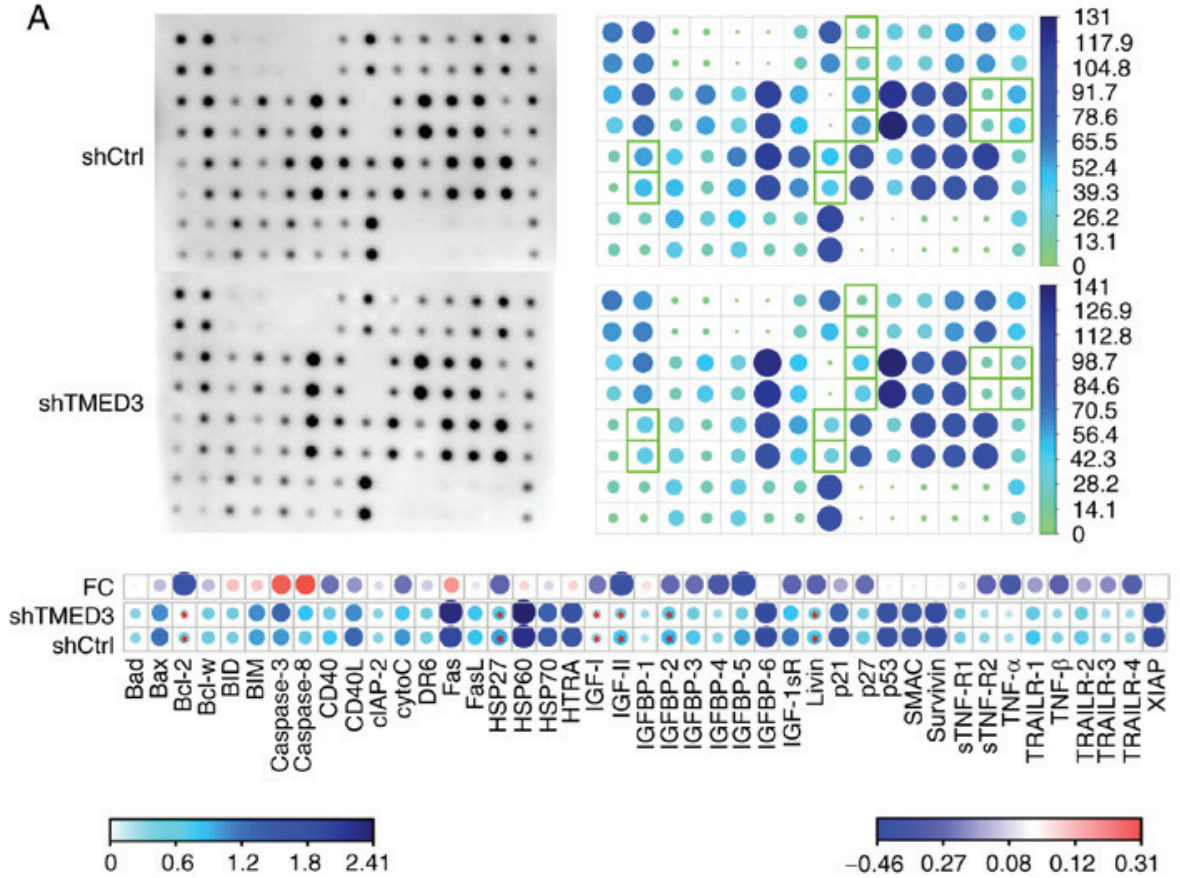

$\begin{array}{lllll}-0.46 & 0.27 & 0.08 & 0.12 & 0.31\end{array}$

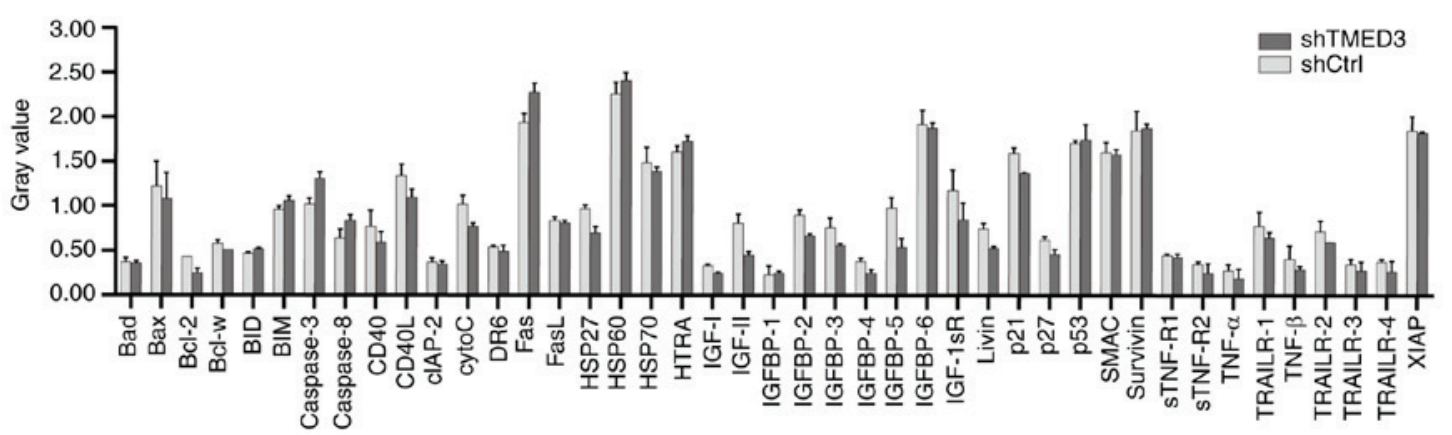

B

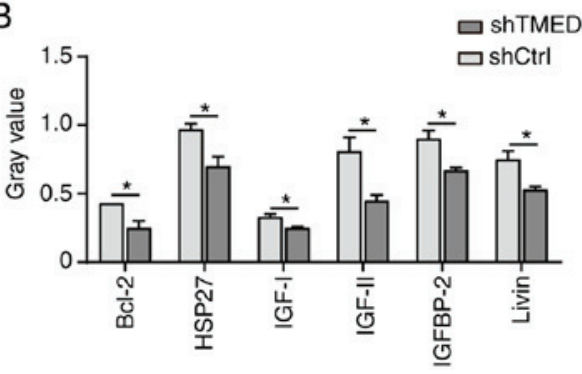

C

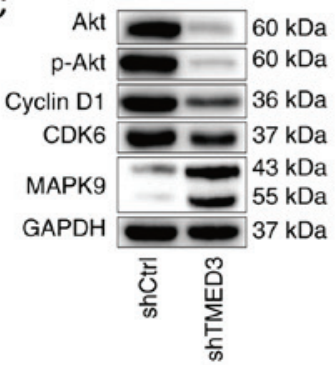

Figure 6. TMED3 regulates the expression of genes involved in the cell cycle, apoptosis and proliferation. (A) Human apoptosis antibody array was performed to identify the effect of TMED3 on downstream genes associated with apoptosis. Proteins encoded by 43 different genes were detected. Dark blue denotes high relative expression and light green denotes low relative expression. FC, red denotes significant upregulation and dark blue denotes downregulation $(\mathrm{P}<0.05$, FC $>20 \%$ or $<-20 \%$ ). (B) Proteins associated with apoptosis, including Bcl-2, HSP27, IGF-I, IGF-II, IGFBP-2 and Livin, were detected in the human apoptosis antibody array and showed significant differential expression. "P<0.05. (C) Western blot analysis was performed to determine the effect of TMED3 on the expression of proteins related to cancer progression. TMED3, transmembrane Emp24 protein transport domain containing 3; sh, short hairpin (RNA); shCtrl, negative control shRNA; HSP27, heat shock protein 27; IGF, insulin-like growth factor, IGFBP2, IGF binding protein 2; p, phosphorylated; FC, fold change.

was distributed mainly in the cytoplasm of surgical specimens. According to data in the Human Protein Atlas (23), TMED3 is located in the Golgi apparatus (data not shown). Given that TMED3 plays a central role in protein trafficking, TMED3 is predicted to be concentrated in the ER and other cytoplasmic regions. In contrast to other cancer types that exhibited positive staining in the nucleus, such as colorectal, lung and breast cancers, IHC staining was weak or negative in the nuclei of surgical chordoma specimens, demonstrating why cancer specificity should be considered. Additionally, the expression of TMED3 was moderately high in chordoma cells. As TMED3 is one of the TMED family members that are important regulators of protein transport, upregulation of TMED3 may promote anterograde and retrograde protein transport via interactions with transmembrane and secreted proteins. It has been reported that TMEDs are upregulated in various cancer types and play different roles in cancer progression (24). As the function of TMED3 in chordoma is unclear, genetic knockdown was performed in order to gain insight into the function of TMED3. Following infection with 
lentiviral vectors targeting TMED3, the viability, migration and cell cycle progression of cells were significantly inhibited, whereas apoptosis was enhanced; additionally, tumor growth in a mouse xenograft model was also inhibited. Evidence obtained from both in vivo and in vitro experiments pointed towards TMED3 serving a role as a positive regulator in chordoma. Consistent with these results, previous studies showed that TMED3 downregulation suppressed cell proliferation and migration in breast cancer, gastric cancer, prostate cancer and hepatocellular carcinoma, and that TMED3 expression is a potential biomarker of poor prognosis in clear cell renal cell carcinoma (12-16). Conversely, Duquet et al (18) showed that TMED3 knockdown induced lung metastasis of HT29 colon cancer cells in vivo, suggesting that TMED3 may serve as a suppressor of colon cancer metastasis. Thus, the complex roles of TMED3 merit further exploration.

In order to investigate the mechanisms underlying the effects of TMED3 in chordoma, after TMED3 silencing, an apoptosis array was used to detect the expression of genes involved in human apoptosis pathways. Apoptosis is the process of programmed cell death, and insufficient apoptosis contributes to the progression of various cancer types (25). According to the protein array, IGF-I, IGF-II and IGFBP-2, which are involved in apoptosis signaling pathways (26), were identified to be downregulated in MUG-Chor1 cells. IGF-I and IGF-II, widely distributed in multiple tissues in humans, bind their receptors with high affinity and subsequently activate a cascade of downstream events, leading to cancer progression by promoting cell proliferation and survival, and tumor growth and metastasis (27). Furthermore, IGFBP2, one of the six members of the IGFBP family that can react with ligands either extracellularly or intracellularly to regulate cell survival and viability, has been reported to serve as an oncogene (26-28). It was reported that overexpression or exogenous IGFBP-2 promoted cell proliferation in metastatic cancer, including glioblastoma and ovarian, prostate and bladder cancers, which was blocked by IGFBP-2 knockdown (29). The present study reported findings consistent with previous studies, suggesting that TMED3 modulates cancer-related genes to inhibit cell apoptosis, leading to chordoma progression. Additionally, Bcl-2, Livin and HSP27, members of the inhibitor of apoptosis protein family, were also observed to be downregulated after knockdown of TMED3 in MUG-Chor1 cells, which was consistent with previous studies and supported the idea that targeting the expression of TMED3 results in apoptosis in chordoma (30-32).

Furthermore, the expression of critical genes associated with signal transduction was analyzed. Western blot analysis revealed that Akt, p-Akt, CDK6 and cyclin D1 were downregulated following TMED3 knockdown, whereas MAPK9 was upregulated, suggesting at a potential relationship with TMED3. Akt, also known as protein kinase B, is a serine-threonine protein kinase that functions as an essential regulator in multiple biological processes, such as metabolism, cell proliferation, cell survival, metastasis and angiogenesis $(33,34)$. It has been demonstrated that Akt reacts with $>100$ substrates by modulating the phosphatase activity of specific groups, and abnormal activation of Akt has been widely observed in different cancer types including prostate, gastric, pancreatic, ovarian and breast cancers (35). A previous study indicated that both PI3K/Akt and RAS/MAPK pathways were activated in chordoma, which was consistent with the present study (36-38).

Additionally, cyclin D1 and CDK6 are associated with the cell cycle, and were downregulated in TMED3-silenced chordoma cells in the present study (39). PI3K and Akt mediate suppression of cyclin D1 threonine residue phosphorylation, inhibiting subsequent ubiquitination to prevent degradation via the RAS signaling pathway, leading to cell cycle progression $(39,40)$. In the present study, chordoma cells infected with shTMED3 were arrested in G2 phase, indicating that TMED3 may regulate the cell cycle via the PI3K/Akt pathway in which CDK6 and cyclin D1 are involved. Conversely, compared with chordoma cells in the shCtrl group, MAPK9 was found to be upregulated in TMED3-silenced cells. MAPK9 (also known as JNK2) is a member of the MAPK family that serves a key role in response to a variety of signals, leading to regulation of multiple signaling pathways in mammalian cells (41). The effects of MAPK9 in cancers depend on the tissue type. MAPK9 was found to be abnormally activated in multiple caner types, including glioma, lung carcinoma, lymphoblastic leukemia and prostate carcinoma, which indicated that MAPK9 critically contributes to cancer progression and development (42). Conversely, in certain cancers, it has reported that MAPK9 plays a role as a negative regulator in cell proliferation via activation of the JNK pathway $(43,44)$. Fan et al $(45)$, for example, showed that specifically inhibiting JNK1/2 expression suppressed the vinblastine-induced phosphorylation of the anti-apoptotic proteins Bcl-2 and Bcl- $\mathrm{X}_{\mathrm{L}}$, leading to inactivation of $\mathrm{Bcl}-2$ and $\mathrm{Bcl}-\mathrm{X}_{\mathrm{L}}$, which may explain why $\mathrm{Bcl}-2$ protein was significantly downregulated in shTMED3 cells in the present study. Based on the findings of the present study, knockdown of TMED3 may inhibit phosphorylation and thus lead to the inhibition of biological processes that contribute to chordoma progression.

In conclusion, it was demonstrated that TMED3 was highly expressed in chordoma, and that knockdown of TMED3 inhibited chordoma progression both in vivo and in vitro by suppressing cell proliferation and migration, and promoting apoptosis. Furthermore, proteins associated with apoptosis signaling pathways, including Bcl-2, HSP27, IGF-I, IGF-II, IGFBP-2 and Livin, were significantly downregulated. Additionally, TMED3 may regulate chordoma via PI3K/Akt or MAPK signaling pathways, as Akt, CDK6, Cyclin D1 and MAPK9 exhibited altered expression following TMED3 silencing. To further determine the potential mechanisms of TMED3, there were plans to perform a bioinformatics analysis using public databases; however, sufficient data was not obtained from the database. The present study doesn't fully explain the underlying upstream mechanisms involved in the effects of TMED3, nor the interactions of the downstream proteins; these issues will be the focus of future studies. Nevertheless, these findings highlighted a potentially important role for TMED3 in chordoma progression and indicated that TMED3 may be a potential target for chordoma therapy.

\section{Acknowledgements}

We gratefully thank Professor Qingling Zhang (Zhujiang Hospital of Southern Medical University) for her academic 
advice. Additionally, we thank Dr Chenyu Zhang (Shanghai Biosciences Co., Ltd.) and Dr Shengjie Zhu (Fudan University) for their help as technical consultants.

\section{Funding}

The present study was supported by the Spine Research Foundation of Zhujiang Hospital (grant no. 20190102).

\section{Availability of data and materials}

The datasets used and/or analyzed during the current study are available from the corresponding author on reasonable request.

\section{Authors' contributions}

JY, YZ and ZC made substantial contributions to the study conception and design. JY, HH, DX and YD were involved in performing the experiments and analyzing the data. $\mathrm{HH}, \mathrm{ZC}$ and $\mathrm{YZ}$ edited and revised the manuscript. All authors read and approved the final manuscript. JY, HH, DX, YD, YZ and $\mathrm{ZC}$ confirm the authenticity of all the raw data.

\section{Ethics approval and consent to participate}

The animal study was conducted according to the Guide for the Care and Use of Laboratory Animals of the National Institutes of Health and approved by the Animal Ethics Committee of Zhujiang Hospital of Southern Medical University (approval no. IACUC-2019010). The human study was approved by the Ethics Committee of Zhujiang Hospital of Southern Medical University (approval no. 2020-KY-030-01). Written informed consent was obtained from all patients enrolled in the study.

\section{Patient consent for publication}

Not applicable.

\section{Competing interests}

The authors declare that they have no competing interests.

\section{References}

1. Sahyouni R, Goshtasbi K, Mahmoodi A and Chen JW: A historical recount of chordoma. J Neurosurg Spine 28: 422-428, 2018.

2. Thanindratarn P, Dean DC, Nelson SD, Hornicek FJ and Duan Z Advances in immune checkpoint inhibitors for bone sarcoma therapy. J Bone Oncol 15: 100221, 2019.

3. Stacchiotti S and Sommer J; Chordoma Global Consensus Group: Building a global consensus approach to chordoma: A position paper from the medical and patient community. Lancet Oncol 16: e71-e83, 2015.

4. Guan JY, He XF, Chen Y, Zeng QL, Mei QL and Li YH: Percutaneous intratumoral injection with pingyangmycin lipiodol emulsion for the treatment of recurrent sacrococcygeal chordomas. J Vasc Interv Radiol 22: 1216-1220, 2011.

5. Kayani B, Hanna SA, Sewell MD, Saifuddin A, Molloy S and Briggs TW: A review of the surgical management of sacral chordoma. Eur J Surg Oncol 40: 1412-1420, 2014.

6. Yang XR, Ng D, Alcorta DA, Liebsch NJ, Sheridan E, Li S, Goldstein AM, Parry DM and Kelley MJ: T (brachyury) gene duplication confers major susceptibility to familial chordoma. Nat Genet 41: 1176-1178, 2009.
7. Stacchiotti S, Tamborini E, Lo Vullo S, Bozzi F, Messina A, Morosi C, Casale A, Crippa F, Conca E, Negri T, et al: Phase II study on lapatinib in advanced EGFR-positive chordoma. Ann Oncol 24: 1931-1936, 2013.

8. Magnaghi P, Salom B, Cozzi L, Amboldi N, Ballinari D, Tamborini E, Gasparri F, Montagnoli A, Raddrizzani L, Somaschini A, et al: Afatinib is a new therapeutic approach in chordoma with a unique ability to target EGFR and brachyury. Mol Cancer Ther 17: 603-613, 2018.

9. Strating JR and Martens GJ: The p24 family and selective transport processes at the ER-Golgi interface. Biol Cell 101: 495-509, 2009.

10. Barr FA, Preisinger C, Kopajtich R and Korner R: Golgi matrix proteins interact with $\mathrm{p} 24$ cargo receptors and aid their efficient retention in the Golgi apparatus. J Cell Biol 155: 885-891, 2001.

11. Connolly DJ, O'Neill LA and McGettrick AF: The GOLD domain-containing protein TMED1 is involved in interleukin-33 signaling. J Biol Chem 288: 5616-5623, 2013.

12. Peng C, Huang K, Liu G, Li Y and Yu C: MiR-876-3p regulates cisplatin resistance and stem cell-like properties of gastric cancer cells by targeting TMED3. J Gastroenterol Hepatol 34: 1711-1719, 2019.

13. Pei J, Zhang J, Yang X, Wu Z, Sun C, Wang Z and Wang B: TMED3 promotes cell proliferation and motility in breast cancer and is negatively modulated by miR-188-3p. Cancer Cell Int 19: 75, 2019.

14. Ha M, Moon H, Choi D, Kang W, Kim JH, Lee KJ, Park D, Kang CD, Oh SO, Han ME, et al: Prognostic role of TMED3 in clear cell renal cell carcinoma: A retrospective Multi-cohort analysis. Front Genet 10: 355, 2019.

15. Zheng H, Yang Y, Han J, Jiang WH, Chen C, Wang MC, Gao R, Li S, Tian T, Wang J, et al: TMED3 promotes hepatocellular carcinoma progression via IL-11/STAT3 signaling. Sci Rep 6: 37070, 2016.

16. Vainio P, Mpindi JP, Kohonen P, Fey V, Mirtti T, Alanen KA, Perälä M, Kallioniemi $\mathrm{O}$ and Iljin K: High-throughput transcriptomic and RNAi analysis identifies AIM1, ERGIC1, TMED3 and TPX2 as potential drug targets in prostate cancer. PLoS One 7: e39801, 2012

17. Mishra S, Bernal C, Silvano M, Anand S and Ruiz IAA: The protein secretion modulator TMED9 drives CNIH4/TGFalpha/GLI signaling opposing TMED3-WNT-TCF to promote colon cancer metastases. Oncogene 38: 5817-5837, 2019.

18. Duquet A, Melotti A, Mishra S, Malerba M, Seth C, Conod A and Altaba AR: A novel genome-wide in vivo screen for metastatic suppressors in human colon cancer identifies the positive WNT-TCF pathway modulators TMED3 and SOX12. EMBO Mol Med 6: 882-901, 2014.

19. Pfaffl MW: A new mathematical model for relative quantification in real-time RT-PCR. Nucleic Acids Res 29: e45, 2001.

20. Livak KJ and Schmittgen TD: Analysis of relative gene expression data using real-time quantitative PCR and the 2(-Delta Delta C(T)) method. Methods 25: 402-408, 2001.

21. Laferriere CA and Pang DS: Review of intraperitoneal injection of sodium pentobarbital as a method of euthanasia in laboratory rodents. J Am Assoc Lab Anim Sci 59: 254-263, 2020.

22. National Research Council (US) Committee for the Update of the Guide for the Care and Use of Laboratory Animals: Guide for the Care and Use of Laboratory Animals. 8th edition. National Academies Press (US), Washington, DC, 2011.

23. Thul PJ, Akesson L, Wiking M, Mahdessian D, Geladaki A, Blal HA, Alm T, Asplund A, Björk L, Breckels LM, et al: A subcellular map of the human proteome. Science 356: eaal3321, 2017.

24. Aber R, Chan W, Mugisha S and Jerome-Majewska LA: Transmembrane emp24 domain proteins in development and disease. Genet Res (Camb) 101: e14, 2019.

25. Wong RS: Apoptosis in cancer: From pathogenesis to treatment. J Exp Clin Cancer Res 30: 87, 2011.

26. Brahmkhatri VP, Prasanna C and Atreya HS: Insulin-like growth factor system in cancer: Novel targeted therapies. Biomed Res Int 2015: 538019, 2015.

27. Simpson A, Petnga W, Macaulay VM, Weyer-Czernilofsky U and Bogenrieder T: Insulin-like growth factor (IGF) pathway targeting in cancer: Role of the IGF axis and opportunities for future combination studies. Target Oncol 12: 571-597, 2017.

28. Bach LA: IGF-binding proteins. J Mol Endocrinol 61: T11-T28, 2018. 
29. Baxter RC: IGF binding proteins in cancer: Mechanistic and clinical insights. Nat Rev Cancer 14: 329-341, 2014.

30. Kasof GM and Gomes BC: Livin, a novel inhibitor of apoptosis protein family member. J Biol Chem 276: 3238-3246, 2001

31. Garrido C, Schmitt E, Cande C, Vahsen N, Parcellier A and Kroemer G: HSP27 and HSP70: Potentially oncogenic apoptosis inhibitors. Cell Cycle 2: 579-584, 2003.

32. Deveraux QL, Schendel SL and Reed JC: Antiapoptotic proteins. The bcl-2 and inhibitor of apoptosis protein families. Cardiol Clin 19: 57-74, 2001.

33. Kandel ES and Hay N: The regulation and activities of the multifunctional serine/threonine kinase Akt/PKB. Exp Cell Res 253: 210-229, 1999.

34. Fresno Vara JA, Casado E, de Castro J, Cejas P, Belda-Iniesta C and Gonzalez-Baron M: PI3K/Akt signalling pathway and cancer. Cancer Treat Rev 30: 193-204, 2004.

35. Hoxhaj G and Manning BD: The PI3K-AKT network at the interface of oncogenic signalling and cancer metabolism. Nat Rev Cancer 20: 74-88, 2020.

36. Tamborini E, Virdis E, Negri T, Orsenigo M, Brich S, Conca E, Gronchi A, Stacchiotti S, Manenti G, Casali PG, et al: Analysis of receptor tyrosine kinases (RTKs) and downstream pathways in chordomas. Neuro Oncol 12: 776-789, 2010.

37. Fry MJ: Phosphoinositide 3-kinase signalling in breast cancer: How big a role might it play? Breast Cancer Res 3: 304-312, 2001

38. Ippen FM, Grosch JK, Subramanian M, Kuter BM Liederer BM, Plise EG, Mora JL, Nayyar N, Schmidt SP, Giobbie-Hurder A, et al: Targeting the PI3K/Akt/mTOR pathway with the pan-Akt inhibitor GDC-0068 in PIK3CA-mutant breast cancer brain metastases. Neuro Oncol 21: 1401-1411, 2019.
39. Sherr CJ, Beach D and Shapiro GI: Targeting CDK4 and CDK6: From discovery to therapy. Cancer Discov 6: 353-367, 2016.

40. Diehl JA, Zindy F and Sherr CJ: Inhibition of cyclin D1 phosphorylation on threonine-286 prevents its rapid degradation via the ubiquitin-proteasome pathway. Genes Dev 11: 957-972, 1997.

41. Yoon CH, Kim MJ, Kim RK, Lim EJ, Choi KS, An S, Hwang SG, Kang SG, Suh Y, Park MJ and Lee SJ: c-Jun N-terminal kinase has a pivotal role in the maintenance of self-renewal and tumorigenicity in glioma stem-like cells. Oncogene 31: 4655-4666, 2012.

42. Bubici C and Papa S: JNK signalling in cancer: In need of new, smarter therapeutic targets. Br J Pharmacol 171: 24-37, 2014.

43. Wu Q, Wu W, Fu B, Shi L, Wang X and Kuca K: JNK signaling in cancer cell survival. Med Res Rev 39: 2082-2104, 2019.

44. Sabapathy K and Wagner EF: JNK2: A negative regulator of cellular proliferation. Cell Cycle 3: 1520-1523, 2004.

45. Fan M, Goodwin M, Vu T, Brantley-Finley C, Gaarde WA and Chambers TC: Vinblastine-induced phosphorylation of Bcl-2 and $\mathrm{Bcl}-\mathrm{XL}$ is mediated by JNK and occurs in parallel with inactivation of the Raf-1/MEK/ERK cascade. J Biol Chem 275: 29980-29985, 2000.

This work is licensed under a Creative Commons Attribution-NonCommercial-NoDerivatives 4.0 International (CC BY-NC-ND 4.0) License. 